\title{
Perspectivas para a Constituição de uma Cultura de Participação em Temas Sociais de Ciência-Tecnologia
}

\section{Perspectives for the Constitution of a Culture of Participation in Social Issues in Science and Technology}

\author{
Suiane Ewerling da Rosa, Roseline Beatriz Strieder
}

Palavras-chave Resumo Na educação ciência-tecnologia-sociedade (CTS) almejaCTS; se, dentre outros objetivos, a democratização das decisões envolvendo Paulo Freire; temas sociais de ciência-tecnologia. Compreendendo que esse PLACTS. propósito está permeado por distintos entendimentos, defendemos uma perspectiva ampliada de participação social. Dessa maneira, o objetivo deste trabalho centra-se em definir e caracterizar elementos que contribuam para situar e constituir mecanismos ampliados de participação em temas sociais que envolvem ciência-tecnologia. Assim, realizamos uma investigação de cunho teórico-prático, fundamentada por referenciais de diferentes campos e da produção da área. Como resultados, situamos essa perspectiva de participação em termos de ação cultural motivada por propósitos transformadores e sinalizamos três elementos - valor, conhecimento e engajamento social - que, articulados entre si, evidenciam indicativos para a sua construção. Portanto, apresentamos problematizações e fundamentações teóricopráticas com relação aos elementos, entendendo que elas podem contribuir para sinalizar e orientar caminhos frente à constituição de processos democráticos ampliados no contexto da educação CTS. 
Keywords Abstract Among other objectives, the science-technology-society STS; movement (STS) in science education aims at the democratization

Paulo Freire; of decisions involving social issues related to science and technology.

Latin American Bearing in mind that such purpose can be understood in different perspective on STS. ways, we defend an expanded perspective of social participation. Thus, the following research focuses on defining and characterizing elements that contribute to situate and constitute expanded mechanisms for participation in social themes that involve sciencetechnology. Therefore, we carried out an investigation of theoretical and practical nature, based on references from different fields of study, including Science Education. As a result, it seems that this perspective of participation in terms of cultural action is motivated by transformative purposes, from which we highlight three constitutive elements: value, knowledge, and social engagement. Subsequently, we present theoretical-practical problematizations and foundations regarding these elements, understanding that they can help chart paths towards the constitution of broader democratic processes in the context of the STS movement in Science Education.

\section{Introdução}

O movimento Ciência-Tecnologia-Sociedade (CTS), assim como a sua repercussão para o âmbito educacional, defende, dentre outros objetivos, a participação da sociedade em temas e problemas reais condicionados pelo desenvolvimento da ciência-tecnologia (Auler, 2011; García et al., 1996; Praia et al., 2007). Apesar de isso estar explícito desde a origem do movimento, associado ao questionamento da atividade científico-tecnológica como neutra e, portanto, da crítica ao modelo de gestão tecnocrática, estudos do campo (a exemplo de Auler, 2011; Rosa, 2019; Roso et al., 2020; Santos \& Auler, 2019; Strieder, 2012) indicam a necessidade de aprofundamentos sobre o que está sendo compreendido por práticas participativas, como alcançá-las e desenvolvê-las em diferentes contextos, em especial no educacional.

Segundo esses estudos, além de pouco evidenciada e praticada em ações educativas fundamentadas pela educação CTS, a participação é, em geral, marcada por discursos reducionistas e pouco críticos. Dentre os discursos reducionistas estão os que evidenciam que a participação em temas sociais de ciência-tecnologia tem sido enfatizada, principalmente, na pós-produção, limitada a uma avaliação (positiva/ negativa) dos impactos da ciência-tecnologia gerados na sociedade (Auler, 2011; Rosa \& Auler, 2016; Santos \& Auler, 2019). Reduzir a participação na pós-produção implica em silenciar ou não problematizar a presença de valores na definição da agenda de pesquisa, nos direcionamentos da atividade científico-tecnológica. Essa dimensão contribui para limitar processos democráticos, reduzindo os mecanismos de participação após a definição do que é essencial e, por isso, tem impactos na busca por redimensionamentos 
de problemas socioambientais e estruturais. Como a atividade científico-tecnológica não é neutra, a participação da sociedade é fundamental em todo o seu processo, que começa na agenda de pesquisa. Portanto, ampliar a participação é um direito humano. No entanto, o que tem sido identificado no âmbito da educação CTS, em especial no contexto brasileiro, é uma ausência de discussões e ações educacionais com ênfase para o papel e concepção dos valores em temas sociais de ciência-tecnologia, elemento que é fundamental e potencializador para mecanismos ampliados de participação (Rosa \& Auler, 2016).

Também, no rol das limitações, destaca-se a ênfase da participação nas práticas CTS associada, em geral, à fala dos estudantes, em uma perspectiva de dar voz aos sujeitos, de possibilitar que o estudante saia de uma condição de não fala, de passividade, para espaços de fala e maior interação no contexto de sala de aula (Rosa, 2019). Essa dimensão, que está relacionada a uma maior interação entre os diferentes sujeitos sociais, apresenta possibilidades para superar a concepção educacional bancária e da cultura do silêncio (Freire, 2005), ou ainda, em uma visão mais ampla, de processos de interação entre ciência e sociedade fundamentados pelo modelo clássico da ciência (Cuevas Badallo \& López, 2019) ou da instrução pública (Samagaia, 2016), em que a comunicação/interação é hierárquica/unidirecional dos cientistas para a sociedade. Porém, na busca por uma democratização ampliada da ciência-tecnologia, a atitude a ser assumida deve ser para além do exposto, privilegiando e construindo atos dialógicos entre os diferentes sujeitos sociais, de processos colaborativos e ações intervencionistas frente a temas de ciência-tecnologia que envolvem demandas sociais.

Assim, os trabalhos mencionados defendem que deveria haver uma preocupação com a participação da sociedade nas agendas de pesquisa, na formulação de políticas públicas para a ciência-tecnologia e, também, a superação da cultura do silêncio, que impossibilita a leitura crítica da realidade, portanto a constituição de sujeitos que tenham voz. Essa perspectiva fundamenta-se nos pressupostos do educador brasileiro Paulo Freire e de referenciais ligados ao Pensamento Latino-Americano em CTS (PLACTS) e ainda que discutida no âmbito de alguns trabalhos, como nas práticas educativas de Archanjo Junior e Gehlen (2020), Gall Centa e Muenchen (2016) e Milli et al. (2018), carece de aprofundamentos e sistematizações, principalmente, sobre as estratégias e os caminhos para a sua promoção, ou seja, de como possibilitar, construir e fortalecer uma cultura de participação em temas sociais de ciência-tecnologia.

As práticas educativas discutidas nos trabalhos citados acima apresentam ações promissoras sobre a participação social, sinalizando um despertar para a problematização e modificação de situações vivenciadas. No entanto, entendendo a necessidade de aprofundamentos que contribuam para o enfrentamento das limitações evidenciadas e de estratégias e sistematizações para a constituição de uma cultura de participação, este trabalho tem como intuito apresentar reflexões sobre a perspectiva ampliada de participação social, defendida no âmbito da educação CTS, em especial no que diz respeito à discussão de elementos fundamentais para a sua constituição na 
educação científica. Em outras palavras, por meio de uma investigação de cunho teórico e problematizador, buscamos encaminhamentos para a seguinte questão: que elementos teórico-práticos sinalizam a construção de uma cultura ampliada de participação em práticas educativas CTS? Assim, além dos propósitos defendidos em Paulo Freire, CTS e PLACTS, apoiamo-nos em referenciais de diferentes campos do saber e em trabalhos da área de Ensino de Ciências, para, com isso, alcançar o objetivo do trabalho, ou seja: definir e caracterizar elementos sinalizadores que contribuam para situar e constituir mecanismos ampliados de participação em temas sociais que envolvem ciênciatecnologia.

\section{Participação Social Ampliada: pressupostos da articulação Freire- CTS e Freire-PLACTS}

A participação, além de ser considerada uma ação essencial para a resolução de problemas sociais, é parte constituinte do ser humano, pois é a partir dela que somos capazes de exprimir desejos, anseios e necessidades, desde um nível mais básico, como forma de pensamento individual, até no âmbito de problemas mais complexos e coletivos. Em geral, ela pode ser entendida como um processo, uma atividade pública, uma ação individual e/ou coletiva da qual se faz parte, toma parte e é parte. No entanto, é possível, e muito comum, "fazer parte sem tomar parte" e é nesse sentido que se reconhece que há diferentes formas de participação, que vão desde níveis mais passivos até atuações mais ativas e críticas, com menor ou maior controle sobre as decisões e direcionamentos (Bordenave, 1994; Teixeira, 2001).

No caso da educação CTS, segundo Strieder (2012), essas diferentes formas podem estar associadas à busca por informação e reconhecimento da presença da ciênciatecnologia na sociedade; ao processo de tomada de decisões individuais ou coletivas, centradas na análise de impactos e transformações sociais; ao reconhecimento das contradições sociais vividas, tendo como intenção o desenvolvimento de mecanismos de pressão, especialmente no processo de produção; ou, ainda, à participação na esfera das políticas públicas, na definição de objetivos e, portanto, voltado para os meios de alcançá-los e formas de controlar sua implementação.

Essa última perspectiva fundamenta-se nos pressupostos do educador Paulo Freire e de referenciais ligados ao PLACTS e está atrelada ao que vem sendo denominado por "cultura ampliada de participação" (Santos \& Auler, 2019).

De acordo com a matriz teórico-filosófica freireana, essa cultura ampliada de participação ocorre a partir da superação da cultura do silêncio, que inviabiliza os sujeitos oprimidos de pronunciarem a sua palavra, negando a participação do ser na sociedade e em seus acontecimentos. Nesse caso, esses sujeitos têm seu papel reduzido para a inserção e aderência naquilo que já é vivido, sem qualquer inferência sobre a realidade. Portanto, são condicionados a situações e atos antidialógicos que refletem, muitas vezes, em silenciamentos de suas vozes, de quem são e de quem poderiam ser. Além disso, na cultura do silêncio, os sujeitos não questionam a realidade, tampouco 
atuam para modificá-la. Logo, contribui para ações culturais que reforçam e sustentam situações de manutenção social.

Como superação dessa cultura, em avanço para ações transformadoras, Freire (2019a) situa a nossa história como tempo de possibilidade, de intervenção, e não de determinação e adequação, pois “o mundo não é. O mundo está sendo" (p. 90, grifos do autor). Nesse caminho das possibilidades, Freire entende que como sujeitos do e com o mundo, constatamos e desvelamos as realidades vividas não para se adaptar a elas, mas para mudá-las, já que não estamos "no mundo, com o mundo e com os outros de forma neutra. Não posso estar no mundo de luvas nas mãos constatando apenas. A acomodação em mim é apenas caminho para a inserção que implica decisão, escolha, intervenção na realidade" (p. 90, grifos do autor). Portanto, parafraseando Freire, a favor do quê? De quem? Contra o que e quem estamos, intervimos e decidimos?

Dentre as possibilidades anunciadas por Freire (1981), como caminho para a superação da cultura do silêncio, está a denúncia de mitos que alimentam a manutenção social, pois para aqueles que desejam a sua preservação, a mitificação é indispensável. Aproximando essas discussões para o contexto educacional CTS, Auler (2002), na articulação dos referenciais Freire-CTS, compara as mitificações com construções históricas que sustentam a suposta neutralidade científico-tecnológica ${ }^{1}$ e que, quando endossadas e reforçadas, geram passividade e alimentam a cultura do silêncio frente a temas sociais de ciência-tecnologia.

Logo, se Freire (2005) propõe a superação da cultura do silêncio como caminho para a constituição de uma sociedade mais justa e democrática, a educação CTS postula, a partir da superação da neutralidade científico-tecnológica, a constituição de mecanismos de participação em temas sociais de ciência-tecnologia. A articulação Freire-CTS, com horizontes para uma cultura participativa, parte do entendimento de leitura crítica do mundo que, dentre outros questionamentos, perpassam problematizações sobre: "a favor de que e quem fazemos ciência" (Freire, 2019a, p. 50). Assim, considerando os problemas sociocientíficos vivenciados, torna-se fundamental a superação de compreensões mitificadas e reducionistas que fortalecem/endossam atitudes passivas e de manutenção, como aquelas associadas à suposta neutralidade (Auler, 2002). Dessa forma, no âmbito das aproximações Freire-CTS defende-se a construção de uma sociedade participativa fundamentada por uma ação cultural de transformação, a qual tem como forma de ação a conscientização, ou seja, do desenvolvimento da consciência crítica, de ação-reflexão e intervenção no mundo (Freire, 1981; 2016).

Considerando que o movimento CTS nasce no hemisfério Norte e teve como preocupação, principalmente, as circunstâncias vividas naquele contexto, e que repercutem até hoje no âmbito educacional brasileiro, conforme resultados apresentados anteriormente em Santos (2016), questiona-se: como pensar uma ação cultural transformadora para a realidade latino-americana? Que demandas representam esse

1 Dentre as diferentes compreensões mitificadas, destacamos: a suposta neutralidade/superioridade do modelo de decisões tecnocráticas; a construção salvacionista/redentora atribuída à ciência-tecnologia; e o determinismo tecnológico. 
contexto e que, muitas vezes, não são anunciadas pelos estudiosos do Norte? Nesse sentido, dar visibilidade para referenciais locais, que anunciam e denunciam demandas específicas vividas localmente, é de extrema importância. Como contribuição a esse diálogo, encontram-se as aproximações entre os pressupostos do PLACTS e a perspectiva educacional de Paulo Freire.

Assim como o movimento do hemisfério Norte, o PLACTS também emerge na década de setenta. No entanto, essa tradição tem como orientação o enfrentamento de problemas locais/regionais, problematizando a política científico-tecnológica dos países da América Latina, em busca de um novo modelo de sociedade. Segundo o PLACTS, há a necessidade de um redimensionamento da política científico-tecnológica da região, que preze e seja coerente com as circunstâncias sociais vivenciadas pelos países latinoamericanos (Dagnino, 2010). Desse modo, seus pressupostos orientadores estavam associados à crítica à transferência tecnológica, à exploração de vantagens, à busca por independência científico-tecnológica e por um redimensionamento da agenda de pesquisa.

Freire dá visibilidade para o desvelamento das contradições sociais, para o enfrentamento de situações-limites ${ }^{2}$, presentes em uma sociedade com marcas colonialistas e imersas em uma cultura do silêncio e busca alternativas transformadoras pelo campo educacional, por meio da denúncia de problemas socioestruturais, marcados pela exclusão, pela opressão, por desigualdades e por injustiças sociais. $\mathrm{O}$ PLACTS, de outra maneira, problematiza a esfera científico-tecnológica a partir de redimensionamentos que incluam demandas locais, ou seja, um repensar da agenda científico-tecnológica com ênfase para essas demandas. Portanto, o PLACTS busca tornar a ciência-tecnologia "um objeto de estudo público, um tópico ligado a estratégias de desenvolvimento social e econômico" (von Linsingen, 2007, p. 7).

Auler e Delizoicov (2015) também destacam as aproximações Freire-PLACTS. Para os autores, essa articulação possibilita dar visibilidade para a separação existente entre concepção e execução. Na crítica freireana, alguns concebem o currículo e outros executam. Porém, para Freire (2018a), a questão fundamental da educação é política, sobre quem decide, sobre quais conteúdos, qual/que tipo de participação os estudantes, pais, comunidade escolar e movimentos populares exercem na educação e em termos de conteúdos programáticos. Por isso, em busca de uma ação cultural transformadora, concepção e execução não podem ser entes separados, há interesses, manifestações valorativas presentes neles. Dessa maneira, conforme já destacado, a questão que se coloca é saber que política é essa, “a favor de quem e de que estará o seu ensino, contra quem, a favor de que, contra quê" (Freire, 2018a, p. 152).

Já na esfera científico-tecnológica, campo não neutro e político, no contexto latino-americano também o que se executa é uma agenda de pesquisa concebida, em geral, no hemisfério Norte. No entanto, tecnologias vindas de realidades diferentes da nossa não se adaptam, necessariamente, às necessidades, estrutura física e social

2 As situações-limites se articulam aos freios e obstáculos que se interpõem na vida dos sujeitos limitando ações sobre a sua própria realidade (Freire, 2005). 
da nossa sociedade (Varsavsky, 1969). Assim, quando problematizamos a separação existente entre concepção e execução na esfera científico-tecnológica, retomamos as discussões de von Linsingen (2007) quando afirma que um dos propósitos centrais do PLACTS fundamenta-se em questionar que tipo de ciência-tecnologia se fala quando nos referimos aos países da América Latina ${ }^{3}$, para que assim se torne possível buscar meios e instrumentos "para o desenvolvimento local do conhecimento científico e tecnológico, de modo a satisfazer as necessidades da região" (von Linsingen, 2007, p. 7).

Portanto, a contribuição para a Educação em Ciências, oriunda da aproximação Freire-PLACTS, encontra-se na crítica da concepção de currículos, de agendas de pesquisa, de definição de demandas sociais e educacionais, de atores sociais envolvidos nos processos decisórios, dos valores e intencionalidades internalizados nos direcionamentos científico-tecnológicos, logo elementos historicamente negligenciados e que a partir dessa aproximação ganham uma maior visibilidade. Dessa maneira, concordamos com Auler e Delizoicov (2015) quando apontam que esses referenciais, apesar de terem suas gêneses e contribuição em campos específicos, constituem-se pressupostos complementares e promissores. Ou seja, a articulação Freire-PLACTS contribui para uma ressignificação de processos e propósitos socioeducacionais, seja na esfera científico-tecnológica, seja na educacional. É válido ressaltarmos que no contexto educacional CTS brasileiro, apesar da aproximação Freire-PLACTS não ser um pressuposto teórico muito presente, já existem pesquisas e ações educativas orientadas por essa articulação, a exemplo de Gall Centa e Muenchen (2016), Milli et al. (2018), Roso (2017), Santos (2016) e Strieder (2012).

Essas reflexões, fundamentadas nas articulações Freire-CTS e Freire-PLACTS, sinalizam caminhos para a constituição de uma cultura ampliada de participação. Se a articulação Freire-CTS contribui para o desvelamento e criticização sobre diferentes dimensões que envolvem ciência-tecnologia, em especial a problematização sobre a não neutralidade, possibilitando uma leitura crítica da realidade, a aproximação FreirePLACTS fundamenta-se, em especial, pela constituição e reinvenção de modelos outros de sociedade, de ciência-tecnologia, de educação, de currículo; esses influenciados por demandas reais do contexto latino-americano, em que a preocupação está na busca por transformações socioestruturais, que incluam interesses comuns e compartilhados com a sociedade.

\section{Encaminhamentos teórico-metodológicos}

Este trabalho caracteriza-se como uma pesquisa de natureza qualitativa que, segundo Moraes e Galiazzi (2016), pode ser entendida como a compreensão de fenômenos investigados a partir de uma análise criteriosa e rigorosa das informações. Portanto, neste trabalho não se pretende "[...] testar hipóteses para comprová-las ou refutá-las ao final da pesquisa; a intenção é a compreensão [...]” (p. 191). Como colocado, trata-se de compreender (definir e caracterizar) elementos que contribuam para situar

3 Paulo Freire, por exemplo, contribui a partir dos desvelamentos de contradições sociais oriundas de investigação temática. 
e constituir mecanismos ampliados de participação em temas sociais que envolvem ciência-tecnologia.

Como encaminhamento teórico-metodológico, a investigação pautou-se pelos pressupostos da Análise Textual Discursiva (Moraes \& Galiazzi, 2016). Esta metodologia foi escolhida por permitir a realização de um diálogo teórico-empírico no processo de pesquisa, marcado pela combinação entre análise rigorosa e síntese subsequente com vistas à produção de novos significados sobre os fenômenos investigados. Além disso, há que destacar sua coerência com os referenciais adotados no presente trabalho, por exemplo, por caracterizar-se por um processo comunicativo (Gonçalves, 2020), pautado por uma visão de ciência não determinista e que rompe com o paradigma dominante (Moraes, 2020).

Orientadas pelas etapas da unitarização, categorização e comunicação, analisamos estudos das mais diversas áreas, representativos de discursos sobre participação social no contexto da educação científica, da ciência-tecnologia e da sociedade de forma mais ampla. Dentre eles, evidenciamos: Auler (2002; 2011), Auler e Delizoicov (2015), Dagnino (2010), Dagnino et al. (1996), Gall Centa e Muenchen (2016), Milli et al. (2018), Roso (2017), Santos (2016), Strieder (2012) e von Linsingen (2007) por contribuírem para a discussão da participação social no contexto da educação CTS e do PLACTS; Freire $(1981 ; 1999 ; 2001 ; 2005 ; 2016 ; 2018 a ; 2018 b)$ pelas fundamentações teóricofilosóficas que possibilitam problematizações sobre o nosso contexto e mecanismos para a constituição cultural de participação, em especial, no contexto educacional; Lacey (2010) e Samagaia (2016) pelas articulações entre a atividade científico-tecnológica e processos democráticos; e Bordenave (1994), Morin (2015), Pateman (1992), Santos (2010), Santos e Avritzer (2002) e Teixeira (2001) por possibilitarem discussões e aprofundamentos referentes aos sentidos e significados dos processos democráticos e participativos em um contexto social amplo.

Além dos estudos referentes aos referenciais mencionados, foi desenvolvida uma análise da produção da área, em especial de práticas educativas CTS brasileiras que foram publicadas nos Anais do Seminário Ibero-Americano em Ciência-Tecnologia-Sociedade no período entre 2010 e 2016. A escolha por esse evento justifica-se pela relevância dele na área e pelo número significativo de práticas educativas. O levantamento dos trabalhos foi realizado a partir da seleção autoidentificada como "prática educativa CTS", realizada na educação básica brasileira, no título, palavras-chave, resumo e quando necessário na introdução e metodologia. Assim, os trabalhos selecionados contêm, de alguma maneira, ações que descrevem e analisam práticas educativas desenvolvidas no Brasil. Desse processo, foram selecionadas quarenta e nove práticas de diferentes instituições e níveis de ensino (corpus de análise) que passaram pela Análise Textual Discursiva, contribuindo para a compreensão da questão em pauta, em especial, para articularmos as discussões oriundas dos estudos anteriormente citados às práticas de sala de aula.

Cabe esclarecer que a análise dessa produção insere-se em uma pesquisa mais ampla (Rosa, 2019), que identificou e caracterizou distintas perspectivas de participação 
social presentes em produções do campo CTS, sendo a cultura ampliada, foco deste artigo, uma delas. Sendo assim, explicitamos que desse universo de quarenta e nove práticas, sete evidenciam, sob diferentes perspectivas, indicativos que nos auxiliaram a pensar limitações e potencialidades quanto a processos democráticos ampliados na e para a educação científica CTS, são elas: Andrade et al. (2016); Cardoso et al. (2016); Ferreira et al. (2016); Gonzalez e Silva (2012); Hartmann e Zimermann (2010); Santos et al. (2016); Silveira et al. (2016). Dessa forma, essas sete produções, em conjunto com os estudos anteriormente mencionados, submetidos a processos de análise e síntese (unitarização, categorização e comunicação), permitiram novos entendimentos sobre os fenômenos investigados, em particular, a identificação e caracterização de elementos teórico-práticos que potencializam a construção de uma cultura ampliada de participação em práticas educativas CTS.

Em concreto, foi realizada a desmontagem dos textos (unitarização) e a identificação de unidades de significado. Essas unidades, organizadas por semelhança em função de seus aspectos importantes, levaram à categorização, seguindo o método da intuição. As categorias, portanto, originaram-se “[...] a partir de inspirações repentinas, "insights" que se apresentam ao pesquisador a partir de uma intensa impregnação nos dados relacionados aos fenômenos." (Moraes \& Galiazzi, 2016, p. 24). A partir da definição dessas categorias, no intuito de descrevê-las e interpretá-las, foram elaborados metatextos, que se configuram os resultados desta pesquisa.

O foco deste trabalho, portanto, está na construção de elementos sinalizadores para a constituição de mecanismos ampliados de participação e não na apresentação de uma sistematização da produção do campo, na linha de uma pesquisa de revisão ou investigação da literatura.

\section{Resultados e Discussões}

A partir da perspectiva freireana, entendemos que a constituição de uma cultura de participação na educação CTS (inédito-viável ${ }^{4}$ ) se dá a partir da visibilidade e problematização de situações e desafios que limitam a sua construção (situaçõeslimite) e da elaboração de estratégias que sinalizem o seu alcance (atos-limites). Assim, fundamentado por uma articulação entre os estudos teóricos mencionados e da análise das práticas educativas CTS, buscamos definir e caracterizar elementos sinalizadores (atos-limites) que contribuam para situar e constituir mecanismos ampliados de participação em temas sociais que envolvem ciência-tecnologia (inédito-viável). Desse processo, resultaram categorias de análise que, conforme caracterização de Moraes e Galiazzi (2016), podem ser denominadas de emergentes, tendo em vista que nesse entendimento as hipóteses são construídas ao longo da investigação. Para expressar o processo analítico deste trabalho, apresentamos a seguir os resultados, portanto, as categorias de análise que estão associadas aos atos-limites valor, conhecimento e

4 Categoria freireana associada a materialização de sonhos, da possibilidade de transformar a realidade a partir do enfrentamento de situações-limites (Freire, 2005; 2014). 
engajamento social, a saber: i) Valores: manifestações e papel em processos decisórios; ii) Conhecimento: concepção e construção para processos decisórios ampliados; e iii) Engajamento Social: sentidos e desafios para práticas participativas.

\section{Valores: manifestações e papel em processos decisórios}

O termo valor possui entendimentos variados e complexos e está imbricado aos diferentes usos nas práticas sociais. Pode estar relacionado a um bem/objeto de valor, a uma qualidade, a um critério para definir escolhas e condutas, a um padrão para avaliar comportamentos, e assim por diante. Independente disso, seu significado, dentre outras questões, está associado ao que sustentamos enquanto sujeitos histórico-sociais. Nessa linha de pensamento, os valores são considerados aspectos que influenciam e estão internalizados nas ações individuais e coletivas, nos interesses dos sujeitos e da sociedade, na forma como pensam, se posicionam e agem. Assim, uma sociedade que manifesta e valoriza em alto grau perspectivas de bem-estar associadas apenas ao olhar individual (de "eu" ter, do que é importante para "mim"), dificilmente manifestará e concretizará, em alto grau, pensamentos e ações solidárias, coerentes com a perspectiva defendida neste trabalho (Lacey, 2010).

Portanto, a constituição de uma cultura ampliada de participação em temas sociais de ciência-tecnologia, que busca o enfrentamento de problemas socioestruturais, como os presentes na América Latina, implica problematizar e internalizar valores orientados por outra lógica, que incluam aspectos coletivos, de cooperação e de justiça social em sintonia com demandas reais da sociedade, em termos de educação, saúde, ambiente, segurança, transporte público, moradia, alimentação, enfrentamento de conflitos sociais, entre outros.

Como contribuição à essa busca, e dialogando com a esfera científico-tecnológica, destacamos os estudos de Lacey (2010), pois eles geram inquietações referentes à: qual ciência e tecnologia queremos e para qual sociedade. Ou seja, suas preocupações centram-se no questionamento da racionalidade dominante e dos valores hegemônicos presentes na esfera científico-tecnológica que tendem a privilegiar certos interesses em detrimento de outros. Para o autor há, principalmente, dois tipos de valores que implicam na concepção e direcionamento da atividade científico-tecnológica: os cognitivos e os sociais. Os valores cognitivos caracterizam-se por critérios a serem satisfeitos por uma boa teoria, como a adequação empírica, poder explicativo, fecundidade, entre outros e deveriam ser predominantes, somente, no momento da avaliação cognitiva das teorias e hipóteses; enquanto os valores sociais, caracterizados pelos aspectos éticos/ sociais/políticos, deveriam predominar nos demais momentos da atividade científicotecnológica.

Porém, Lacey (2010) destaca que a perspectiva valorativa racionalmente sustentada hoje, na ciência moderna, tem incorporado, principalmente, valores associados ao controle de objetos naturais e ao avanço tecnológico, esses postos como meio para solucionar uma variedade cada vez maior de problemas. Essas manifestações 
se articulam ao que o autor denomina de valorização moderna de controle (VMC) e tem sido manifestada em alto grau em todas as partes do mundo. A VMC está subscrita pelas instituições econômicas predominantes, servindo para determinados valores, em geral, os associados ao contexto neoliberal, portanto valores que endossam às práticas do mercado global, ao individualismo, aos lucros, à mercantilização, à eficiência econômica, ao favorecimento do sistema capitalista (Lacey, 2010).

Contudo, compreende-se que essa perspectiva valorativa dificulta a identificação/ desvelamento de problemas sociais e processos decisórios para o seu enfrentamento. Os valores apenas cognitivos e/ou que reforçam a VMC, por exemplo, tendem a silenciar ou reduzir esses problemas e possíveis encaminhamentos alternativos. Logo, atividades científico-tecnológicas que buscam o bem-estar coletivo e justiça social não podem ser formuladas apenas pelo domínio e manifestação discursiva de valores cognitivos ou orientados pela VMC (Lacey, 2010). Em outras palavras, para a efetivação de direcionamentos transformadores não será qualquer manifestação valorativa que a implicará, mas àquelas associadas à solidariedade, à sustentabilidade, à cooperação, ou seja, uma defesa pela "democracia participativa englobando a formal e os direitos políticos e civis em relação dialética com os direitos sociais, econômicos e culturais" (Lacey, 2010, p. 190).

Complementando essas discussões, Cardoso et al. (2020) destacam que o desenvolvimento autêntico discutido por Lacey, que é aquele que considera as estruturas sociais e econômicas que atendam as reais necessidade humanas, compreendido como a "medida do bem-estar da maioria das pessoas de uma dada localidade" (Cardoso et al., 2020, p. 15), está vinculado, principalmente, pelas manifestações de valores coletivos, como os já citados. Perspectiva que para os autores revela aproximações com os propósitos do PLACTS, pois compreendem que a busca pelo desenvolvimento autêntico evidencia a necessidade de ampliar a participação social, em especial, na agenda de pesquisa.

Coerente com exposto e como caminho sinalizador para a constituição de uma cultura participativa ampliada, destacamos, também, as experiências orientadas pelo PLACTS, como as fundamentadas pela Tecnologia Social (TS) ${ }^{5}$. Suas ações centramse na socialização dos bens e serviços, na democratização das decisões incluindo grupos heterogêneos, no engajamento das comunidades produtoras e usuárias para a produção conjunta de conhecimento científico-tecnológico e internalização de valores e demandas compartilhados com a sociedade nos direcionamentos da ciência-tecnologia (Dagnino, 2010; Roso, 2017). A Tecnologia Social está marcada pela possibilidade

5 Esclarecemos que, recentemente, Renato Dagnino, autor que participou da formulação original do conceito de Tecnologia Social, passou a usar a expressão Tecnociência Solidária para se referir às formas de materializar o desenvolvimento tecnocientífico, na perspectiva por ele defendida (Dagnino, 2019). Segundo autor, essa mudança fez-se necessária porque a expressão Tecnologia Social passou a ser empregada de maneira equivocada e distante da sua proposta original, que estava voltada "à produção e ao consumo de bens e serviços em redes de economia solidária, respeitando seus valores e interesses, para satisfazer necessidades coletivas" (Dagnino, 2019, p. 63). Como este estudo é anterior ao que Dagnino explicita essas considerações, decidimos utilizar a expressão inicial, mantendo-nos fiéis aos termos utilizados nos trabalhos nos quais nos fundamentamos, em especial em Roso (2017) e Dagnino (2010), mesmo concordando com a necessidade de conceber um novo conceito. 
de inclusão social e de construir alternativas aos procedimentos formais da lógica da competitividade que leva a uma insustentabilidade social, ambiental e econômica. Dessa maneira, essa perspectiva tem sido entendida como uma "democracia para além da representação. Ou seja, em TS está sendo praticado algo há muito defendido na educação CTS: a democratização de processos decisórios envolvendo CT (ciência-tecnologia)!" (Roso, 2017, p. 98). E ainda, concordamos com Roso (2017) quando sinaliza que as práticas orientadas pela Tecnologia Social podem contribuir de maneira significativa para transformações socioeducacionais CTS. Essa proposição, portanto, permite pensar novas configurações de formação dos sujeitos, organizadas por problematizações e exercício curricular que envolva valores outros, oriundos de demandas sociais e dos sustentados pelas práticas democráticas participativas, e não apenas os constitutivos da ciência e os manifestados em alto grau na sociedade, como os valores individuais e do mercado. Aspectos, portanto, que quando problematizados e expressos contribuem para pensar formas alternativas de organização social.

A busca por articular essas reflexões sobre valores e atividade científicotecnológica, ao contexto da educação científica, nos leva à matriz teórico-filosófica de Paulo Freire. Nesse sentido, destacamos as problematizações realizadas por Freire, relacionadas aos diferentes valores presentes na sociedade (Freire, 2005; 2016; 2018a; 2019a; 2019b). Suas denúncias alertam para a estrutura social e econômica vivida no contexto latino-americano, que dificulta a verbalização e manifestação de valores que representem um repensar e modificar as circunstâncias existentes. Para esse autor, as manifestações sociais, influenciadas pela lógica colonialista, de relações hierárquicas, de poder e de dependências, reproduzem, em alto grau, silenciamentos sobre as diferentes formas de injustiças, desigualdades e opressão, sustentando valores individuais/pessoais. Complementando essas discussões, Freire (2019a) chama a atenção para o fato de que é impossível pensar/aceitar "uma democracia fundada na ética do mercado que, malvada e só deixando excitar pelo lucro, inviabiliza a própria democracia" (p. 55, grifo do autor). E ainda, se o modelo de desenvolvimento social, denunciado por Freire, já na década de sessenta, constitui um ambiente favorável à produção, este não soube "criar mecanismos eficientes de distribuição" (Freire, 2019b, p. 19).

Assim, Freire nos ajuda a pensar em valores que manifestam e potencializam perspectivas de compromisso social, de denúncia da realidade excludente e anúncio de possibilidades para ela (Freire, 2014), isso porque, conforme já anunciado, "somos seres no mundo, com o mundo, e com os outros, por isso seres da transformação e não da adaptação a ele" (Freire, 2019a, p. 37, grifos do autor). Portanto, segundo o autor, se "minha terra é dor de milhões, é fome, é miséria, é esperança também de milhões igualmente famintos de justiça" (Freire, 2019a, p. 42). O desvelamento e transformação da realidade implica decisão, "tomada de posição, ruptura, opção" (Freire, 2019a, p. 43), logo uma cultura de participação balizada por outros valores. Implica, também, em considerar como base os valores emitidos pelos educandos, como sinalizado por Santos e Gehlen (2020). 
Nessa perspectiva, portanto, uma “[...] ação transformadora deve considerar o fenômeno a partir da voz do sujeito para que se evidenciem as demandas e necessidades emergentes de sua condição existencial, viabilizando uma práxis dialética [...]" (Santos \& Gehlen, 2020, p. 345). A identificação e compreensão crítica desses valores pode pautar-se no processo de Investigação Temática, considerando falas significativas dos estudantes problematizadas em diálogos decodificadores, na linha do discutido em Archanjo Junior e Gehlen (2020), Milli et al. (2018) e Santos et al. (2019).

Referente às proposições, considerando o corpus de análise, destacamos o desenvolvimento de uma prática CTS que teve como ênfase dar visibilidade para problemas socioestruturais vividos pelos sujeitos da comunidade escolar, marcado pela desigualdade socioeconômica (Hartmann \& Zimmermman, 2010). Dentre os propósitos orientadores para a ação educativa, chamamos a atenção para o papel social da ciênciatecnologia como potencializador para refletir e problematizar sobre a contradição social identificada.

Como ponto de partida da prática educativa, foram realizadas ações de desvelamento da realidade vivida naquela comunidade, obtendo como resultado o perfil socioeconômico dos estudantes e suas famílias e a identificação de baixo quando comparado com outras regiões próximas à escola. Motivados por isso e articulados por um trabalho colaborativo e solidário entre as famílias e a comunidade escolar, eles desenvolveram um projeto com intuito de proporcionar um repensar sobre a contradição identificada e de um retorno socioeconômico para a própria comunidade. Ou seja, as ações desenvolvidas incluíram manifestações valorativas, em geral, não presentes nas configurações curriculares tradicionais, possibilitando, dessa maneira, um desvelar, pensar e atuar coletivamente sobre problemas sociais daquela comunidade.

Acreditamos que as discussões realizadas contribuem para pensarmos a constituição de uma cultura ampliada de participação, essa em construção no campo CTS e que é fortalecida quando manifestações de diferentes valores se fazem presentes e são internalizadas nos processos decisórios. No entanto, e à guisa de síntese, é válido explicitarmos quais manifestações valorativas são necessárias para a constituição de uma cultura ampliada de participação. Que valores possibilitam, de fato, um desenvolvimento autêntico? Nesse sentido, conforme discussões realizadas, destacamos os valores fundamentados por uma perspectiva ético-crítica, como os pautados pelos pressupostos freireanos, ou seja, aqueles orientados pela solidariedade, amorosidade, respeito e justiça social. Valores alicerçados pelas práticas da participação popular, do respeito à diversidade e da emancipação humana, logo valores que potencializam e fortalecem a constituição de processos democráticos participativos (Lacey, 2010). Fundamentado pelos referenciais apresentados neste trabalho, defende-se que essa internalização seja o ponto de partida para direcionamentos e concepção de agendas de pesquisa, de currículos, de práticas educativas e sociais, pois serão essas experiências e vivências que permitirão que outros valores também sejam manifestados, em alto grau, na sociedade, possibilitando, dessa maneira, um repensar sobre os rumos dela, de educação, de ciência-tecnologia. 


\section{Conhecimento: concepção e construção para processos decisórios ampliados}

O conhecimento, assim como os aspectos valorativos, possui a capacidade de influenciar e direcionar processos decisórios. A depender da forma como é concebido e construído, o conhecimento possibilita sustentar, argumentar e contra-argumentar posicionamentos que podem ser usados para manutenção ou transformação de um problema, pois os diferentes conhecimentos, racionalidades e formas de construções implicam em propósitos distintos. Portanto, na constituição de processos democráticos ampliados, ter conhecimento é necessário para a sociedade atuar e se posicionar criticamente frente a questões decisórias (Santos \& Avritzer, 2002). No entanto, que conhecimentos, racionalidades e construção são necessários?

Se, por um lado, questionamos decisões pautadas, essencialmente, em senso comum e crenças, por outro, defendemos a superação de decisões tecnocráticas fundamentadas, unicamente, pela dimensão técnico-científica. Ou seja, defende-se neste trabalho a constituição de práticas socioeducacionais balizadas por conhecimentos técnico-científicos, mas também a articulação com outras dimensões, pois "o domínio técnico é tão importante para o profissional quanto a compreensão política o é para o cidadão. E não é possível separar um do outro" (Freire, 2019b, p. 44, grifos do autor).

Assim, a construção de uma cultura de participação, orientado pelas aproximações Freire-CTS e Freire-PLACTS, requer uma nova forma de conceber e produzir conhecimentos. Dessa maneira, como colaboração a esse objetivo, destacamos os estudos de Morin (2015) e Santos (2010), pois eles contribuem para problematizar a supremacia de uma racionalidade associada a um pensamento lógico de sujeitos individuais/isolados, de um sistema de regras e/ou uma garantia de verdade absoluta, isolada de qualquer interferência social.

Essa racionalidade, de acordo com Morin, contribuiu para a anulação da diversidade, fazendo com que o pensamento simplificado fosse incapaz de fazer a conjunção do uno e do múltiplo, refletindo no que o autor chama de inteligência cega, ou seja, aniquilação dos conjuntos e totalidades, isolamento dos objetos com o seu meio ambiente, "[...] As realidades-chave são desintegradas. Elas passam por entre fendas que separam as disciplinas" (Morin, 2015, p. 12). O que se busca, nesta racionalidade, é colocar ordem no universo, através de uma lei e princípio, expulsando dele toda a desordem. Essa forma de conceber e conduzir o conhecimento consegue ver o uno e o múltiplo, mas não o fato de que o uno pode ser ao mesmo tempo o múltiplo, logo o conhecimento científico desvela a simplicidade por trás da multiplicidade e da aparente desordem dos fenômenos.

Considerada como modelo totalitário de conceber e conduzir o conhecimento, essa racionalidade "nega o caráter racional a todas as formas de conhecimento que se não pautarem pelos seus princípios epistemológicos e pelas suas regras metodológicas" (Santos, 2010, p. 21). O método científico se fundamenta na redução da complexidade, em que as leis privilegiam aspectos do como funciona, ao invés de qual o agente ou o fim 
das coisas. Para Santos (2010), nesta lógica, o conhecimento é embasado pela ordem e estabilidade do mundo, assim o passado se repete no futuro. O determinismo mecanicista é o horizonte de uma forma de conhecimento utilitário e funcional, e a concepção e condução do conhecimento estão fundamentadas pela universalidade, que considera apenas uma ciência geral e não abre espaços para aspectos locais/singulares. Junto a isso, reduz unidades elementares que constituem um sistema de conhecimento, dando ênfase à soberania do determinismo universal (ordem). Este pensamento sustenta-se pelo isolamento/separação do objeto com relação ao ambiente, separação entre objeto e sujeito, garantia da objetividade científica e eliminação do ser e da existência, a partir de meios quantificáveis e de formalização (Morin, 2015; Santos, 2010). Logo, a concepção/construção/direcionamento do e com o conhecimento só devem pertencer a especialistas, ideologicamente neutros, que por estarem imersos na cultura científica hegemônica conduzem de maneira eficiente os princípios e metodologias que regem essa racionalidade.

Como alternativa a essa forma de pensamento, Morin destaca a complexidade, entendida não por estar completa, mas sim pela própria incompletude do conhecimento e Santos (2010) propõe o paradigma emergente, ou seja, um conhecimento prudente para uma vida decente.

Como somos seres sociais, físicos, biológicos, culturais, psíquicos, ao mesmo tempo e em transformação, "a complexidade é aquilo que tenta conceber a articulação, a identidade e a diferença de todos esses aspectos" (Morin, 2014, p. 176). Diferentemente do pensamento simplificado, que visa a separação ou unificação por uma redução, o pensamento complexo compreende que o todo necessita das partes e as partes necessitam do todo. A complexidade se apresenta como desordem, ambiguidade, incerteza, logo o conhecimento tem função de "ordenar os fenômenos rechaçando a desordem, afastar o incerto, isto é, selecionar os elementos da ordem e da certeza, clarificar, distinguir, hierarquizar [...]" (Morin, 2014, pp. 13-14). No entanto, essas operações, que são necessárias à inteligibilidade, caso eliminem os outros aspectos do complexus ("o que é tecido junto"), podem provocar "cegueiras" e, por conseguinte, um pensamento reducionista/limitador da realidade vivida.

Santos (2010), de outra maneira, esclarece o paradigma emergente a partir de quatro teses, que são: i) todo o conhecimento científico-natural é científico-social; ii) todo o conhecimento é local e total. A fragmentação não é disciplinar, mas temática constituída por grupos sociais, projetos de vida, em que "os temas são galerias por onde os conhecimentos progridem ao encontro um dos outros" (Santos, 2010, p. 76); iii) todo o conhecimento é um autoconhecimento, logo a ciência repercute a condição existencial da sociedade; e iv) o conhecimento científico visa constituir-se em senso comum. Este isolado é um saber conservador e pode levar prepotências, mas dialogado com o conhecimento científico tem capacidade para gerar uma nova racionalidade, feita de racionalidades. 
Diante do exposto, defende-se que a busca por processos democráticos em temas sociais de ciência-tecnologia perpassa reconhecer e assumir que a concepção, condução e papel do conhecimento se entrelaçam com as racionalidades acima descritas. Entendese que o conhecimento científico-tecnológico é essencial, mas insuficiente, pois será visto como adequado aos temas sociais vivenciados se estiver articulado com a integração e ampliação de diferentes variáveis, não restrita, dessa forma, às científicas. Organizar o pensamento a partir de racionalidades contribui, inclusive, para colocar em pauta problemas, demandas locais historicamente ignoradas na concepção e produção do conhecimento científico. Demandas e conhecimentos que passam a ser considerados democraticamente e necessitam de um olhar complexo, de coletivos interdisciplinares, de galerias temáticas que se encontram e dialogam.

$\mathrm{Na}$ articulação dos referenciais Freire-CTS, Freire-PLACTS e da Tecnologia Social, há uma busca por conceber e construir conhecimentos tendo como horizonte processos democráticos. Em sintonia com esse propósito e como caminho estratégico e potencializador para essa construção encontram-se os trabalhos de Callon (1998) e Samagaia (2016), os quais defendem a construção colaborativa entre sujeitos e conhecimentos. Os saberes individualizados/locais dão conta de situações singulares, mas sozinhos tendem a limitar/reduzir a compreensão, posicionamento e argumento sobre um problema social em processos decisórios. Na racionalidade democrática, o conhecimento está imbricado com diferentes dimensões: é concebido por demandas sociais/locais, articulado com valores diversos e construído por diferentes saberes e vozes, esses interagindo de forma dialógica e colaborativa. O conhecimento, nessa perspectiva, se articula a ideia de "co-laboração" freireana, em que a construção se associa à própria problematização referente à que e para quem serve o saber que está sendo produzido, e é constituído nas relações entre os sujeitos e deles com o mundo, nas relações de transformação, que é aperfeiçoado na problematização crítica destas relações (Freire, 2006).

As dimensões anunciadas, quando articuladas entre si, possibilitam o processo de coprodução de saberes e coaprendizagem entre os sujeitos, estratégias basilares para a constituição de uma cultura de participação ampliada. Aspectos anunciados, também, nos pressupostos da Tecnologia Social, pois, conforme Roso (2017), a autonomia, tomada de decisões, coaprendizagem e reaplicação são elementos essenciais para a transformação social e processos democráticos. Aspectos exercitados e evidenciados, por exemplo, na experiência educativa desenvolvida por Archanjo Junior e Gehlen (2020), onde as articulações dos pressupostos de Paulo Freire e da Tecnologia Social guiaram a concepção e execução das ações.

Além dessa prática, destacamos a ação educativa relatada por Hartmann e Zimmermman (2010), do nosso corpus de análise, que também evidencia aproximações com os aspectos apresentados. As autoras destacam que o projeto colocou os estudantes em situações desafiadoras mobilizando-os para construírem conhecimentos frente à demanda local identificada. Dessa forma, a construção do conhecimento, que se 
fundamentou sobre bases interdisciplinares da área de ciências da natureza, da ciências humanas e dimensões outras, ocorreu a partir de um processo que envolveu diferentes sujeitos, suas vozes e seus saberes (estudantes, familiares, comunidade escolar). Além disso, a prática evidenciou indicativos de ações dialógicas e de um desenvolvimento colaborativo que foi acontecendo "à medida que os alunos buscam relacionar os conhecimentos dentro de um projeto que tem por critério a pesquisa, a interface entre diferentes disciplinas e a aplicação social" (Hartmann \& Zimmermman, 2010, p. 7). Dessa forma, a prática revela indicativos promissores dos propósitos socioeducacionais de Paulo Freire e da Tecnologia Social, como o fortalecimento da comunidade para promover conhecimento novo a partir de suas necessidades e da inclusão de coletivos interdisciplinares.

Por fim, compreendemos que a educação como um elemento de cidadania requer entendê-la como um ato político, de possibilidades e práticas participativas que visam a construção de uma consciência crítica, de emancipação e transformação social (Freire, 2001). Complementar a isso, a construção de uma sociedade democrática exige do sistema educacional a formação de pessoas que atuem em processos decisórios, que tenham responsabilidade e compromisso frente aos problemas e circunstâncias sociais (Santomé, 2010). Logo, para isso, é necessário estabelecer uma relação diferente entre conhecimento e sociedade. É nesse sentido que a educação CTS precisa assumir o compromisso de compartilhar e construir conhecimentos não restritos a reducionismos e simplificações, pois essa racionalidade limita qualquer constituição de sujeitos críticos e participativos frente a temas sociais de ciência-tecnologia. Deste modo, a construção de mecanismos ampliados de participação requer/exige um compromisso duplo com o conhecimento: verbalizar e problematizar os reducionismos presentes em uma racionalidade hegemônica e totalitária e sua influência na sustentação/reforço de modelos tecnocráticos, e promover processos de coaprendizagem e coprodução de conhecimentos oriundos de racionalidades democráticas, essas preocupadas com desvelamentos, entendimentos e enfrentamentos de problemas reais e contemporâneos vivenciados.

\section{Engajamento Social: sentidos e desafios para práticas participativas}

Nestetrabalho, o engajamentosocial, comoelemento sinalizadorpara constituição de uma cultura de participação, está relacionado com o desenvolvimento de atitudes e espaços que promovem a escuta, a comunicação, a intervenção e a mobilização de ações. Paulo Freire (1981; 1999; 2005; 2016; 2018a; 2018b), Bordenave (1994) e Teixeira (2001) foram os estudiosos que embasaram nossas discussões, contribuindo para caracterizar e discutir os sentidos e significados referentes a esse elemento. É válido destacar que, ao longo do nosso estudo, identificamos diferentes perspectivas de engajamento social, desde àquelas relacionadas a um despertar motivacional, com o objetivo de promover uma maior interação entre os professores e estudantes, e desses com os objetos de conhecimento, desenvolvendo atitudes comunicativas, até mobilizações e intervenções 
nas realidades vividas, visando ações sociopolíticas transformadoras. Essa última, mais próxima do que estamos denominando de engajamento como práxis social, e que tem como pano de fundo as aproximações Freire-PLACTS.

Considerando, portanto, que há diferentes compreensões sobre o engajamento social, evidenciamos, inicialmente, o entendimento fundamentado por Bordenave (1994), o qual refere-se às diferentes atitudes e ações que podem ser desenvolvidas em contextos participativos. Para o autor, elas podem ocorrer desde uma esfera passiva, como a informacional e de uma comunicação unilateral, até mais ativa, como ações consultivas, de recomendação, compartilhamento e autonomia dos sujeitos.

ReferenteaomovimentoCTS, oengajamentosocialtambémemergecomoelemento sinalizador para a constituição de processos democráticos. Enquanto propósito, buscase o desenvolvimento de atitudes responsáveis e fundamentadas por conhecimentos e valores relevantes, de consciência e compromisso social, e a respectiva transformação desses aspectos em ação (Santos \& Mortimer, 2002). Assim, o engajamento social está associado às interações, atitudes e ações estabelecidas pelos sujeitos e deles com os temas sociais de ciência-tecnologia. Imbricado com as manifestações valorativas, da forma de conceber e construir o conhecimento, dos espaços e interações sociais possibilitados, o engajamento social pode resultar em formas inativas/passivas até progressivamente mais ativas e críticas.

Para elucidar e aprofundar aspectos que se aproximam do objetivo deste trabalho, recorremos, novamente, à matriz teórico-filosófica freireana. Nessa perspectiva, engajamento é a articulação indissociável entre conscientização, compromisso histórico e práxis social; logo uma prática dialética para transformações das realidades vividas (Streck et al., 2016). Conscientização entendida não como "pílula mágica a ser aplicada em doses diferentes com vistas à mudança” (Freire, 1999, p. 114), mas como processo de criticização das relações consciência-mundo, como "comprometimento humano diante do contexto histórico-social". É ir além da tomada de consciência, pois essa não é ainda conscientização, visto que ela "consiste no desenvolvimento crítico da tomada de consciência” (Streck et al., 2016, p. 88).

Dessa maneira, no contexto de uma cultura ampliada de participação, o engajamento social fundamenta-se por processos de conscientização e é assumido como práxis social que envolve não apenas o desvelamento da realidade vivida (consciência crítica), mas, junto a ela, como processo dinâmico e dialético, mudanças socioestruturais. Práxis que se constitui na "estreita relação que se estabelece entre um modo de interpretar a realidade vivida e a consequente prática que decorre desta compreensão levando a uma ação transformadora" (Streck et al., 2016, p. 325). Portanto, enquanto práxis social, o engajamento não está associado a atitudes e ações "essencialmente práticas", de um "agir por agir", sem análises profundas delas, mas é precedido de uma criticização da realidade e de situações desafiadoras e limitadoras e da consequente ação sobre ela. Propósito constituído por ações e atitudes dinamizadas por práticas dialógicas, de açãoreflexão e pela busca de autonomia, ou seja, quando os sujeitos desenvolvem o nível de 
consciência máxima, conforme anunciado por Paulo Freire, e isso permite uma análise crítica e transformadora da sua realidade (Freire, 2018b). Logo, o engajamento social consiste em ações e atitudes sociopolíticas que incidem em novas formas de pensar/ler e agir no mundo, se contrapondo a alienação, silenciamentos, invasão, domesticação, submissão, atos antidialógicos e hierarquizados, pois quando assumidos e disseminados reforçam a passividade e a cultura do silêncio.

Considerando então que o engajamento social está articulado ao desvelamento da realidade e de uma atuação transformadora, as interações entre os sujeitos e deles com o objeto cognoscível devem ser ativas e críticas. Assim, a atitude a ser assumida é para além de "falar e ser ouvido", de alguém que "concede voz", para atitudes dialógicas, construtivas, problematizadoras, colaborativas e que propiciem ações sociopolíticas. Para isso, os sujeitos precisam "ter voz", estar em um coletivo que valorize a escuta sensível e ativa, que fortaleça exercícios de vozes, pois é dessa maneira que será possível "estar presente na História e não simplesmente nela estar representadas" (Freire, 1999, p. 75). Visando isso, no contexto educacional, as ações devem buscar uma leitura crítica e pertencimento dos sujeitos frente a realidade experienciada e a condição ontológica por um ser mais. Ou seja, libertação/enfrentamento de situações e circunstâncias limitadoras, das situações-limites, em busca de humanização (Freire, 2005), e ainda de denúncia da realidade vivida, excludente e desumanizadora, e anúncio de possibilidades, modificando o mundo e a nós mesmos (Freire, 2019a).

Dessa forma, o engajamento social, como elemento potencializador para a constituição de uma cultura de participação ampliada, é fomentado pelo nível de consciência máxima possível, da problematização e superação de situações-limites. É uma práxis autêntica. Logo, não pode ser constituído no “blábláblá", nem no ativismo, mas é pautado pela unidade dinâmica e dialética entre ação e reflexão. É um compromisso histórico-social, pois "não é no silêncio que os homens se fazem, mas na palavra, no trabalho, na ação-reflexão" (Freire, 2005, p. 108). Portanto, por ser uma práxis autêntica, o engajamento social implica uma relação indissociável entre teoria e prática, entre reflexão e ação para agir e transformar a realidade vivida, tornando a história caminho de possibilidades e não de determinismos. A indissociabilidade não implica imediatismo, mas tem como referência a complexidade que compõe a realidade. Isso porque, conforme aponta Silva (2011), mesmo que em um contexto diferente, "uma práxis emancipadora só pode ser construída se a atividade for modificada em sua forma (aparência) e em seu conteúdo (essência)" (Silva, 2011, p. 23).

No entanto, currículos tradicionais/engessados, desvinculados das contradições e realidades sociais, assim como percepções/compreensões que reforçam visões reducionistas sobre ciência-tecnologia, distanciam-se do alcance desses propósitos. Por isso que a definição dos temas ${ }^{6}$ que compõem currículos e agendas, oriunda, por exemplo, do processo de investigação temática, a partir do qual se obtém os temas geradores, conforme anunciado pelas aproximações Freire-PLACTS, é considerado

6 Na perspectiva das aproximações Freire-CTS e PLACTS, entende-se que os temas identificados, problematizados e trabalhados referem-se a problemas de demandas sociais/locais. 
potencializador para tomada de consciência sobre a realidade vivida e transformação dela. Isso porque investigar o tema implica "o pensar dos homens referido à realidade, é investigar seu atuar sobre a realidade, que é sua práxis" (Freire, 2005, p. 56). Nesse processo, a atuação de diferentes sujeitos é essencial, e é fortalecida quando começa na própria definição do tema, quando diferentes atores sociais, em geral silenciados, passam a ter voz e a engajar-se no processo de investigação da própria realidade, do planejamento, desenvolvimento e intervenção das ações.

Essa forma de conceber e constituir o engajamento encontra sintonia, também, com os propósitos da Tecnologia Social. Trazendo essas discussões para um repensar de configurações curriculares, Roso (2017) destaca a investigação de demandas sociais, orientados pela Tecnologia Social, a partir do processo de investigação temática freireana. Nessa, os diferentes sujeitos, suas demandas e saberes fazem parte de todo o processo, mas não na perspectiva de "dar voz", mas de exercícios de vozes, de práticas dialógicas que ecoam e refletem as situações-limite, demandas e leituras de mundo. Os protagonismos não se restringem a determinados sujeitos, como nos modelos tecnocráticos, mas é de toda a comunidade, pois é isso que possibilitará um caminhar para processos democráticos emancipatórios e críticos.

No rol de práticas educativas CTS presentes no nosso corpus de análise e que nos ajudam a pensar sobre contradições vividas pela sociedade, fortalecendo atitudes e ações sociopolíticas, está a prática descrita por Andrade et al. (2016). Nesse trabalho, embora não haja referência às aproximações Freire-CTS, Freire-PLACTS ou ainda menção à Tecnologia Social, como um dos indicativos, destacamos a construção de um engajamento orientado para conscientização, mobilização e busca por modificação de situações vivenciadas.

Como destaque, evidenciamos a constituição de ações e atitudes que possibilitaram questionar práticas tradicionais de agricultura e sua relação com o modelo de desenvolvimento atual, esse marcado/sustentado por valores que reforçam a valorização moderna de controle (Lacey, 2010). Essas ações permitiram dar visibilidade para um repensar da organização social, econômica e ambiental através de um processo de criticização orientado pelas práticas e valores agroecológicos, esses fundamentados por valores coletivos/solidários. Os sujeitos se engajaram em diferentes ações sociopolíticas, diretas e indiretas ${ }^{7}$, mas chamamos a atenção para as dificuldades que eles tiveram para realizar ações de mobilização cívica que questionavam o modelo agrícola hegemônico. A não viabilidade de atuação (engajamento social) dos estudantes em um desfile cívico potencializou diálogos sobre as dificuldades da participação quando aspectos que questionam os interesses de alguns segmentos sociais (manifestações valorativas) são explicitados. Conforme já evidenciamos, o engajamento social se situa na possibilidade

7 Fundamentado em Hodson (2011), às ações diretas se articulam ao uso de "bicicleta ao invés de carro, comprar alimento orgânico ao invés de alimento produzido à base de agrotóxicos, destinar o lixo à reciclagem, realizar compostagem, desligar as luzes, utilizar sacos verdes para ir ao supermercado, dentre outras". Já as indiretas, voltam-se para "aprovar uma lei para banir o uso de agrotóxicos nos alimentos, realizar petição contra o uso de agrotóxicos, realizar visita a agricultores para discutir sobre o assunto, dentre outras” (Andrade et al., 2016, p. 1090). 
de problematizar contradições sociais e da consequente ação sobre ela, aspectos potencializados pela prática. Pois, mesmo não sendo possível o desenvolvimento de ações no âmbito cívico (naquele momento), a prática possibilitou desvelar uma contradição social vivida, muitas vezes, silenciada e que limita e dificulta ações sociopolíticas, como as "relações de poder e jogos de interesses existentes na sociedade" (Andrade et al., 2016, p. 1093), promovendo uma nova forma de ver/ler temas de ciência-tecnologia que envolvem contradições sociais e quando possível atuar sobre eles. Ou seja, aspectos coerentes com o defendido nas aproximações dos referenciais anunciados neste trabalho.

Embora as dificuldades para realizar ações sociopolíticas, de transformar a leitura crítica sobre a realidade em atitudes e ações, estejam presentes em diferentes contextos, as discussões e a prática educativa realizadas, revelam potenciais significativos para a construção e formação de novos sujeitos, esses mais engajados socialmente. Se almejamos, cada vez mais, mecanismos ampliados de participação, precisamos dar visibilidade e problematizar as limitações e potencialidades existentes, conforme evidenciado na prática descrita. Isso porque, a constituição de uma participação ampliada, como a defendida neste trabalho, não é estabelecida por atitudes e ações supostamente neutras, mas estão imbricadas com outros elementos, como valores, conhecimento, espaços institucionais ou não que possibilitam ela. É almejando essa constituição, embora cientes de seus desafios, que propomos refletir e problematizar sobre ela e sobre elementos que podem sinalizar e fortalecer a busca por essa ação cultural. Demandas necessárias e urgentes frente ao alcance de propósitos transformadores.

\section{Considerações Finais}

Nosso intuito ao longo do trabalho foi dar visibilidade para um tema, em geral, verbalizado, mas negligenciado em termos de aprofundamentos e implicações socioeducacionais na Educação em Ciências, em especial na linha CTS, que é a constituição de processos participativos ampliados em temas sociais de ciênciatecnologia. Como contribuição a essa demanda, realizamos um exercício teóricoprático balizado por referenciais de diferentes campos e da produção da área, a partir dos pressupostos da Análise Textual Discursiva. Assim, caracterizamos uma perspectiva de participação social e chamamos a atenção para elementos que emergiram no nosso estudo como sinalizadores para a sua constituição, quais sejam: valor, conhecimento e engajamento social.

Por fundamentar, endossar e orientar nossos desejos, direcionamentos e atuações, o elemento valorativo emergiu articulado ao potencial que ele tem, quando internalizado e manifestado socialmente, para influenciar, sustentar e/ou ressignificar práticas decisórias. Por possibilitar compreender, influenciar e direcionar decisões, o elemento conhecimento também foi identificado nessa investigação, isso porque é inviável construir processos democráticos sem acesso, entendimento e apropriação dele. Já o engajamento social manifestou-se relacionado ao desenvolvimento e potencialização para mobilizações, atitudes e ações frente a processos decisórios. Assim, imbricado com o processo de conscientização, o engajamento, articulado aos outros elementos, 
possibilita novas formas de ler/ver e atuar sobre circunstâncias vividas.

Embora este trabalho tenha dado ênfase para referenciais que situam perspectivas críticas sobre os elementos e suas contribuições para pensarmos a participação social, compreendemos que há diferentes formas de conceber, entender e pensar sobre eles e desenvolver ações educativas que repercutem isso. Em outras palavras, há percepções sobre os elementos que se distanciam do propósito descrito, possibilitando recaídas/ reforço aos modelos tecnocráticos e uma cultura do silêncio, ou ainda perspectivas reducionistas de participação, como os apresentados em Rosa (2019) e Rosa e Strieder (2021). Nesse sentido, pautado por aprofundamentos e exercícios teóricos e práticos, identificamos diferentes ênfases com relação aos elementos valor, conhecimento e engajamento social. Articulados entre si, os elementos e as ênfases possibilitam constituir diferentes culturas de participação, desde aquelas que buscam a motivação dos estudantes com temas de ciência-tecnologia, a apropriação e avaliação dos seus produtos, amenização de impactos, até um repensar e modificar problemas socioestruturais vivenciados.

Logo, os elementos (valor, conhecimento e engajamento social) e as culturas de participação, quando vistos à luz dos referenciais Freire-CTS e Freire-PLACTS, podem ser sistematizados por um espectro de criticidade. Porém, neste trabalho, a ênfase esteve em dar visibilidade ao que denominamos cultura ampliada de participação, uma perspectiva orientada por propósitos socioeducacionais transformadores. Para isso, os elementos precisam ser vistos, problematizados e assumidos de maneira crítica, e é nesse sentido que entendemos que os referenciais e os aprofundamentos descritos neste trabalho, mesmo com os diferentes desafios presentes, podem contribuir. Além disso, embora haja outros aspectos envolvidos e necessários, acreditamos que a articulação entre os elementos tem potenciais significativos para orientador/sinalizar a constituição de uma cultura ampliada de participação.

Por fim, dentre os diferentes desafios presentes na educação CTS destacamos uma das suas principais reivindicações/objetivo, que é a busca por uma maior participação da sociedade em processos decisórios em temas sociais da área científicotecnológica e a efetivação em termos de ações socioeducacionais. Assim, como contribuição, apresentamos as discussões realizadas e o potencial que elas possuem para orientar e ressignificar configurações curriculares, práticas educativas e a própria atividade científico-tecnológica coerente com esse desafio. Além do mais, como aspecto potencializador deste trabalho, destacamos referenciais, em geral, não discutidos e aprofundados na educação CTS, como as aproximações Freire-PLACTS e a Tecnologia Social. Embora recente na área, práticas fundamentadas por esses referenciais, como os destacados no texto, têm evidenciado caminhos potencializadores para pensarmos uma cultura ampliada de participação no contexto educacional CTS, os quais, neste trabalho, foram articulados ao que denominamos elementos sinalizadores.

Além dessas práticas, destacamos que há outras, não fundamentadas nos referenciais supracitados e que também indicam perspectivas (potencialidades e 
limitações) para a sala de aula frente à constituição do propósito discutido neste trabalho, a exemplo de Hartmann e Zimmermman (2010) e de Andrade et al. (2016), descritas anteriormente. Com isso, explicitamos que há vários caminhos/métodos/metodologias possíveis que, de uma outra maneira, contemplam a abordagem de um ou dos três elementos (valor, conhecimento e engajamento social), na perspectiva apontada neste trabalho.

\section{Referências}

Andrade, M., Conrado, D., Nunes-Neto, F., \& Almeida, R. (2016). Abordagem sobre Agrotóxicos em uma Sequência Didática Colaborativa baseada em Questões Sociocientíficas. Indagatio Didactica, 8(1), 1083-1097. https://doi.org/10.34624/ id.v8i1.3666

Archanjo Junior, M. G. A., \& Gehlen, S. T. (2020). A Tecnologia Social e sua Contribuição para a Educação em Ciências. Revista Brasileira de Pesquisa em Educação em Ciências, 20(1), 345-374. https://doi.org/10.28976/1984-2686rbpec2020u345374

Auler, D. (2002). Interações entre Ciência-Tecnologia-Sociedade no Contexto da Formação de Professores de Ciências. (Tese de Doutorado, Universidade Federal de Santa Catarina, Florianópolis, Santa Catarina). Repositório Institucional da UFSC. http://repositorio. ufsc.br/xmlui/handle/123456789/82610

Auler, D. (2011). Novos caminhos para a educação CTS: ampliando a participação. In W. L. P. Santos, D. Auler (Orgs.). CTS e educação científica: desafios, tendências e resultados de pesquisas (pp. 73-98). UnB.

Auler, D., \& Delizoicov, D. (2015). Investigação de temas CTS no contexto do pensamento latino-americano. Linhas Críticas, 21(45), 275-296. https://doi.org/10.26512/ lc.v21i45.4525

Bordenave, J. (1994). O que é participação (6a ed.). Brasiliense.

Callon, M. (1998). Des différentes formes de démocratie technique. Responsabilité \& Environnement, 9(1), 63-73.

Cardoso, A., Caluzi, J., \& Santos, R. (2020). Aproximação entre a filosofia de Hugh Lacey e o campo educacional em ciência, tecnologia e sociedade. Ensaio - Pesquisa em Educação em Ciências, 22(1), 1-26. https://doi.org/10.1590/21172020210127

Cardoso, Z., Abreu, R., \& Strieder, R. (2016). Lixo Eletrônico: uma proposta CTS para o ensino médio. Indagatio Didactica, 8(1), 1610-1626. https://doi.org/10.34624/ id.v8i1.3523

Cuevas Badallo, A., \& Urueña López, S. (2019). Públicos y actores en la democratización de la actividad científica. Revista Iberoamericana de Ciencia, Tecnología y Sociedad CTS, 14(42), 9-29. 
Dagnino, R. (2010). Um dilema latino-americano: ciência e tecnologia para a sociedade ou adequação sócio-técnica com o povo? In R. Dagnino (Org.). Estudos Sociais da Ciência e Tecnologia e Política de Ciência e Tecnologia: abordagens alternativas para uma nova América Latina. EDUEPB.

Dagnino, R. (2019). Tecnociência solidária: um manual estratégico. Lutas Anticapital.

Dagnino, R., Thomas, H., \& Davyt, A. (1996). El pensamiento en ciencia, tecnología y sociedad en Latinoamérica: una interpretación política de su trayectoria. REDES, 3(7), $13-51$.

Ferreira, A., Quadros, A., \& Rodrigues, V. (2016). Ensino a partir de temas: é favorecida a apropriação de conceitos científicos? Indagatio Didactica, 8(1), 1098-1113. https://doi. org/10.34624/id.v8i1.4665

Freire, P. (1981). Ação Cultural para a Liberdade (5a ed.). Paz e Terra.

Freire, P. (1999). A educação na cidade (3a ed.). Cortez.

Freire, P. (2001). Política e Educação (5a ed.). Cortez.

Freire, P. (2005). Pedagogia do Oprimido (48 ${ }^{\mathrm{a}}$ ed.). Paz e Terra.

Freire, P. (2006). Extensão ou Comunicação? (13a ed.). Paz e Terra.

Freire, P. (2014). Pedagogia dos sonhos possíveis. Paz e Terra.

Freire, P. (2016). Conscientização. Cortez.

Freire, P. (2018a). Pedagogia da Esperança: um reencontro com a Pedagogia do Oprimido (24 ed.). Paz e Terra.

Freire, P. (2018b). Educação e mudança (30a ed.). Paz e Terra.

Freire, P. (2019a). Pedagogia da Indignação: cartas pedagógicas e outros escritos (5ª ed. ). Paz e Terra.

Freire, P. (2019b). À Sombra desta Mangueira (12a ed.). Paz e Terra.

Gall Centa, F., \& Muenchen, C. (2016). O Despertar para uma Cultura de Participação no Trabalho com um Tema Gerador. Alexandria: Revista de Educação em Ciência e Tecnologia, 9(1), 263-291. https://doi.org/10.5007/1982-5153.2016v9n1p263

García, M. G., Cerezo, J. A. L., \& López, J. L. L. (1996). Ciencia, Tecnologia y Sociedad: una introducción al estudio social de la Ciencia y la tecnología. Tecnos.

Gonçalves, F. P. (2020). Análise textual discursiva como constituinte de um processo de comunicação. Revista Pesquisa Qualitativa, 8(19), 722-738. https://doi.org/10.33361/ RPQ.2020.v.8.n.19.370

Gonzalez, I., \& Silva, J. (2012). Desenvolvimento de Conceitos e Valores na Decisão sobre o Uso de Drogas. III Seminário Ibero-Americano em Ciência-Tecnologia-Sociedade. Madrid/Espanha: AIA-CTS. 
Hartmann, A., \& Zimmermann, E. (2010). CTS no ensino médio: aplicação de CひT na realidade social. II Seminário Ibero-Americano em Ciência-Tecnologia-Sociedade. Brasília/Brasil: AIA-CTS.

Lacey, H. (2010). Valores e atividade científica 2. Editora 34.

Lacey, H., \& Mariconda, P. (2014) O modelo da interação entre as atividades científicas e os valores na interpretação das práticas científicas contemporâneas. Estudos Avançados, 28(82), 181-199. https://doi.org/10.1590/S0103-40142014000300012

Milli, J., Almeida, E., \& Gehlen, S. (2018). A Rede Temática e o Ciclo Temático na Busca pela Cultura de Participação na Educação CTS. Alexandria: Revista de Educação em Ciência e Tecnologia, 11(1), 71-100. https://doi.org/10.5007/1982-5153.2018v11n1p71

Moraes, R. (2020). Avalanches reconstrutivas: movimentos dialéticos e hermenêuticos de transformação no envolvimento com a análise textual discursiva. Revista Pesquisa Qualitativa, 8(19), 595-609. https://doi.org/10.33361/RPQ.2020.v.8.n.19.372

Moraes, R., \& Galiazzi, M. (2016). Análise Textual Discursiva. Unijuí.

Morin, E. (2014). Ciência com consciência (16 ed.). Bertrand.

Morin, E. (2015) Introdução ao Pensamento Complexo (5ªed.). Sulina.

Pateman, C. (1992) Participação e Democracia. Paz e Terra.

Praia, J., Gil-Perez, D., \& Vilches, A. (2007). O papel da natureza da ciência na educação para a cidadania. Ciência e Educação, 13(2), 141-156. https://doi.org/10.1590/S151673132007000200001

Rosa, S. (2019). Educação CTS: contribuições para a constituição de culturas de participação. (Tese de Doutorado, Universidade de Brasília, Brasília, Distrito Federal). Repositório Institucional da UnB. https://repositorio.unb.br/handle/10482/39240

Rosa, S., \& Auler, D. (2016). Não Neutralidade da Ciência-Tecnologia: Problematizando Silenciamentos em Práticas Educativas Relacionadas à CTS. Alexandria: Revista de Educação em Ciência e Tecnologia, 9(2), 202-231. https://doi.org/10.5007/1982$5153.2016 \mathrm{v} 9 \mathrm{n} 2 \mathrm{p} 203$

Rosa, S., \& Strieder, R. (2021). Culturas de participação em práticas educativas brasileiras fundamentadas pela educação CTS. Revista Iberoamericana de Ciencia, Tecnología y Sociedad - CTS, 16(47), 71-94.

Roso, C. (2017). Transformações na Educação CTS: uma proposta a partir do conceito de tecnologia social. (Tese de Doutorado, Universidade Federal de Santa Catarina, Florianópolis, Santa Catarina). Repositório Institucional da UFSC. https://repositorio. ufsc.br/handle/123456789/187060

Roso, C., Auler, D., \& Delizoicov, D. (2020). Democratização em Processos Decisórios sobre CT: O Papel do Técnico. Alexandria Revista de Educação em Ciência e Tecnologia, 13(1), 225-249. https://doi.org/10.5007/1982-5153.2020v13n1p225 
Samagaia, R. (2016). Comunicação, divulgação e educação científicas: Uma análise em função dos modelos teóricos e pedagógicos. (Tese de Doutorado, Universidade Federal de Santa Catarina, Florianópolis, Santa Catarina). Repositório Institucional da UFSC. https://repositorio.ufsc.br/xmlui/handle/123456789/169089

Santomé, J. (2013). Currículo, justiça e inclusão. In J. Sacristán (Org). Saberes e Incertezas sobre o Currículo. Penso.

Santos, B. de S. (2010). Um discurso sobre as ciências (7 $7^{\mathrm{a}} \mathrm{ed}$.). Cortez.

Santos, B. de S., \& Avritzer, L. (2002) Para ampliar o cânone democrático. In B. Santos (Org.). Democratizar a democracia: os caminhos da democracia participativa. Civilização Brasileira.

Santos, J. S., Lima, J. A., Barbosa, L. dos S., \& Gehlen, S. T. (2019). A Dimensão Axiológica na Elaboração de uma Rede Temática na Educação Infantil: Contribuições para o Ensino de Ciências. Revista Brasileira de Pesquisa em Educação em Ciências, 19, 649-682. https://doi.org/10.28976/1984-2686rbpec2019u649682

Santos, J., Conrado, D., \& Nunes-Neto, N. (2016). Questões sociocientíficas no ensino fundamental de ciências: uma experiência com poluição de águas. Indagatio Didactica, 8(1), 1051-1067. https://doi.org/10.34624/id.v8i1.3657

Santos, R. A. (2016). Busca de uma Participação Social para além da Avaliação de Impactos na Ciência-Tecnologia na Sociedade: sinalizações de práticas educativas. (Tese de Doutorado, Universidade Federal de Santa Maria, Santa Maria, Rio Grande do Sul). Repositório Digital da UFSM. http://repositorio.ufsm.br/handle/1/3513

Santos, R. A., \& Auler, D. (2019). Práticas educativas CTS: busca de uma participação social para além da avaliação de impactos da Ciência-Tecnologia na Sociedade. Ciência \& Educação, 25(2), 485-503. https://doi.org/10.1590/1516-731320190020013

Santos, W. L. P., \& Mortimer, E. F. (2002). Uma Análise de Pressupostos Teóricos da Abordagem C-T-S (Ciência - Tecnologia - Sociedade) no Contexto da Educação Brasileira. Ensaio: Pesquisa em Educação em Ciências, 2(2), 110-132. https://doi. org/10.1590/1983-21172000020202

Santos. J., \& Gehlen, S. (2020). Os valores na pesquisa em Educação em Ciências e indicativos para uma prática educacional ético-crítica. Investigações em Ensino de Ciências, 25(1), 329-357. http://dx.doi.org/10.22600/1518-8795.ienci2020v25n1p329

Silva, K. (2011). A formação de professores na perspectiva crítico-emancipadora. Revista Linhas Críticas, 17(32), 13-31. https://doi.org/10.26512/lc.v17i32.3668

Silveira, M., Palácio, R., \& Conrado, D. (2016). Aplicação de questões sociocientíficas como estratégia para o ensino sobre energia elétrica. Indagatio Didactica, 8(1), 10331050. https://doi.org/10.34624/id.v8i1.3651 
Streck, D., Redin, E., \& Zitkoski, J. (2016). Dicionário Paulo Freire (3a ed.). Autêntica.

Strieder, R. (2012). Abordagem CTS na Educação Científica no Brasil: Sentidos e Perspectivas. (Tese de Doutorado, Universidade de São Paulo, São Paulo, São Paulo). Biblioteca Digital de Teses e Dissertações da USP. https://teses.usp.br/teses/ disponiveis/81/81131/tde-13062012-112417/pt-br.php

Teixeira, E. (2001). O local e o global: limites e desafios da participação cidadã. Cortez. Varsavsky, O. (1969). Ciencia, política y cientificismo. Centro Editor de América Latina. von Linsingen, I. (2007). Perspectiva educacional CTS: aspectos de um campo em consolidação na América Latina. Ciência \& Ensino, 1(número especial), 1-19.

\author{
Suiane Ewerling da Rosa \\ Universidade Federal do Oeste da Bahia \\ Barreiras, Bahia, Brasil \\ suiedr@gmail.com \\ Roseline Beatriz Strieder \\ Universidade de Brasília \\ Brasília, Distrito Federal, Brasil \\ roseline.unb@gmail.com
}

Editora Responsável

Maíra Batistoni e Silva

Manifestação de Atenção às Boas Práticas Científicas e de Isenção de Interesse

Os autores declaram ter cuidado de aspectos éticos ao longo do desenvolvimento da pesquisa e não ter qualquer interesse concorrente ou relações pessoais que possam ter influenciado o trabalho relatado no texto. 